\title{
Study of the Post-Vaccination Anti-hbv Immune Response in the Health Staff of the Souro Sanou University Hospital in Bobo-Dioulasso
}

\author{
Sourabié $\mathbf{Y}^{1,2 *}$, Siribié $\mathbf{M}^{3}$, Gomgnimbou $\mathrm{MK}^{2,4}$, Sanou $\mathrm{G}^{5}$, Ouédraogo $\mathrm{MS}^{1,2}$, Fumoux $\mathrm{F}^{6}$ and Traoré $\mathrm{Y}^{7}$ \\ ${ }^{1}$ Centre Hospitalier Universitaire Sourô Sanou 01 BP 676 Bobo 01 Burkina Faso \\ ${ }^{2}$ Institut supérieur des sciences de la santé, Université Nazi Boni de Bobo Dioulasso, Burkina Faso \\ ${ }^{3}$ Unité de Formation et de Recherche en Sciences et Technologies, Université Catholique de l'Afrique de l'Ouest, Burkina Faso \\ ${ }^{4}$ Centre Muraz, Burkina Faso \\ ${ }^{5}$ Centre National de Formation et de Recherche sur le Paludisme, Burkina Faso \\ ${ }^{6}$ Unité de Formation et de Recherche en Sciences et Technologies, Université Joseph Ki-Zerbo \\ ${ }^{7}$ Aix Marseille Université, France \\ *Corresponding author: Yacouba Sourabié, Professor-researcher in Immunology at Higher Institute of Health Sciences, Nazi \\ BONI University of Bobo Dioulasso; Souro Sanou Hospital Center, Department of Immunology and Hematology BP 676, Tel: \\ 0022670710325, Email: yacourabie@yahoo.fr
}

\section{ARTICLE INFO}

Received: 慧 January 06, 2020

Published: 㓞 January 21, 2020

Citation: Sourabié Y, Siribié M, Gomgnimbou MK, Sanou G, Ouédraogo MS, Fumoux F, Traoré Y. Study of the PostVaccination Anti-hbv Immune Response in the Health Staff of the Souro Sanou University Hospital in Bobo-Dioulasso. Biomed J Sci \& Tech Res 24(4)-2020. BJSTR. MS.ID.004094.

Keywords: Vaccine; HBV; Anti-HBs Ab

\section{ABSTRACT}

Introduction: Post immune response again VHB after immunization has been slowly reported in health personal in low income country. We aimed to evaluate the post-vaccination immune response against the hepatitis B virus in health personal at CHUSS Bobo-Dioulasso.

Methods and patients: This were a prospective cohort study that was conducted from March 2014 to January 2015 at CHUSS. Thus, 84 vaccinated subjects were included. Whole blood was collected from each subject for antibody determination. CMIA technology was used to perform an anti-HBs antibodies determination. Subjects with a titer of less than $100 \mathrm{mIU} / \mathrm{ml}$ were considered non-protective in the hospital setting.

Results: Subjects average age is $40.38 \pm 9.82$ years. The sex ratio is 2.23 . Of these, $47.6 \%$ had an anti-HBs antibodies titre greater than $100 \mathrm{mIU} / \mathrm{ml}$ and considered very well immunized. Also, 52.4\% had an anti-HBs antibodies titre less than $100 \mathrm{mIU}$ / ml; and considered as unprotected subject in a hospital setting. Of these, $27.38 \%$ had a titer of between 10 and $99 \mathrm{mIU} / \mathrm{ml}$ and 30\% had a titer of less than $10 \mathrm{mIU}$ / ml. Comparing the different proportions of non-responders according, we find that there is no statistically significant difference between non-responders aged $\leq 40$ years compared to those aged $>40$ years $(p=0.8)$. Comparing the different proportions of non-responders according sex, we find that there is a statistically significant difference between male and female non-responders $(\mathrm{p}=0.044)$.

Conclusion: We found that about half of the subjects had satisfactory protection, which indicates a good efficacy of SHANVAC B®. Research on immunological nonresponders should be pursued to identify possible causes. 


\section{Introduction}

Hepatitis B virus Infection is a major public health problem in Burkina Faso; the prevalence is $8.8 \%$ Tao et al. [1,2]. Subjects at risk with hepatitis B virus infection must be vaccinated. After immunization of a subject, 4 to 8 weeks after the last injection, the presence in the plasma of antibodies directed against the HBs antigen provides immunological protection against infection if the anti-HBs level is greater than $10 \mathrm{mIU} / \mathrm{mL}$ WHO, [3]. However, 5 to $10 \%$ of subjects are non-responders (no antibody response after vaccination or less than $10 \mathrm{mIU} / \mathrm{mL}$ ) or small responders (moderate response that rapidly disappears) according to WHO. These subjects are real subjects at risk for the hepatitis B virus. In addition to this provision, a special recommendation of antibody titer is made for groups said to risk with regard to their socioprofessional activities. These include health workers, newborns of HBs Ag positive mothers, parenteral drug users, sex workers, etc. The recommendation proposes that these individuals have an anti-HBs antibodies titer of at least $100 \mathrm{mIU} / \mathrm{mL}$ to be considered protected High Council of Public Health [4]. Caregivers in Burkina Faso, a geographical area of high prevalence and high transmission, thus accumulate the risk of contamination as exposed to daily life.

As a result, since 2013, Burkina Faso's Ministry of Health has practiced vaccination against hepatitis B on a large scale among people at risk of contamination, who are engaged in a professional activity in health facilities. Thus, health personal of the CHU Sourô Sanou of Bobo Dioulasso has been immunized against hepatitis $B$ (SHANVAC $B^{\circledR}$ vaccine). It must be effectively protected to preserve its health and not be a source of contamination for patients. We will call non-immunological responders (NRs) subjects with an anti-HBs titer of less than $100 \mathrm{mIU} / \mathrm{ml}$. Those with a titer greater than or equal to $100 \mathrm{mIU} / \mathrm{ml}$ will be said to be good responders High Council of Public Health [4]. This study aims to determine the rate of health workers appropriately protected after vaccination. The general objective is to evaluate the proportion of good responders from CHUSS health staff who received the HBV vaccine (SHANVAC B ${ }^{\circledR}$ ).

\section{Methods and Patients}

This is a prospective study conducted over a period of ten months that included 84 subjects at CHUSS Bobo Dioulasso. Our study population comes from health staff of the Sourô Sanou University Hospital Center who received the SHANVAC B ${ }^{\circledR}$ vaccine in 2013. The vaccinated subjects were included at random. Peripheral whole blood was collected on a tube without anticoagulant. Serum obtained was used to perform the detection of anti-HBs antibodies. Architect CI4100 ${ }^{\circledR}$ (Abbott, Wiesbaden, Germany.) has been used for the detection of anti-HBs antibodies. Its principle is based on a particulate micro immunoassay technique by chemiluminescence thus allowing the detection of the desired markers. Anon-responder at the health care staff had been defined by anti- HBs antibodies titer of less than $100 \mathrm{mIU} / \mathrm{ml}$ and a responder is defined by an anti-HBs antibodies titer greater than $100 \mathrm{mIU} / \mathrm{ml}$.

\section{Ethic Statement}

Samples analyzed in our study derived from medical personal that went to laboratory for post immunization of VHB control. The results of the various examinations were given to the participants of the study. The study was approved by the National Ethic Committee for health research of Health Ministry in Burkina Faso Ouagadougou. Patients participating in this study gave written informed consent.

\section{Statistical Analysis of Data}

Data were analyzed using Wilcoxon test to compare rates. We used Fischer $(\mathrm{t})$ test for the percentages. Nonparametric tests (Kruskal Wallis and Mann-Whitney) were used when normality of distribution wasn't verified. Results were considered statistically significant when $\mathrm{p}<0.05$. Analysis was performed in SPSS version 23 (SPSS Inc., Chicago, IL).

\section{Results}

\section{Socio-Demographic Characteristics}

In this study, 84 subjects were included. Average age of the subjects is $40.38 \pm 9.82$ years. Subjects under 40 years represent $53.57 \%$ compared to $46.43 \%$ aged $>40$ years. Overall, most of the study participants were males $69.05 \%$ (58/84) compared to $30.95 \%$ (26/84) for female. The sex ratio was 2.23 . Also, $90.5 \%$ of subjects received 2 doses while $9.5 \%$ received 3 doses. Anti-HBs titers ranged from 0 to $1000 \mathrm{mIU} / \mathrm{mL}$. The geometric mean of the anti-HBs titer is $301.20 \mathrm{mIU} / \mathrm{mL}$ (95\% CI, 217.95 - $384.45 \mathrm{mIU}$ / $\mathrm{mL}$ ). Subjects with an anti-HBs antibodies titer of less than 10 $\mathrm{mIU} / \mathrm{mL}$ (non-responder generics) accounted for $22.62 \%$ versus $77.38 \%$ for subjects with a titer $\geq 10 \mathrm{mIU} / \mathrm{ml}$. For non-responders in health care settings, we found $52.4 \%$ of non-responders with an anti-HBs antibodies titer of less than $100 \mathrm{mIU} / \mathrm{ml}$ compared to $47.6 \%$ of subjects with a titer greater than or equal to $100 \mathrm{mIU} /$ $\mathrm{mL}$ (good responders).

\section{Factors Associated with The Post-Vaccination Immune Response}

\section{Impact of Age on The Immunogenicity of the Vaccine}

Comparing the different proportions of non-responders according age, we find that there is no statistically significant difference between non-responders aged $\leq 40$ years compared to those aged $>40$ years $(p=0.8)$.

(Figure 1) Distribution of subjects by age group and immunogenicity.

\section{Impact of Sex on The Immunogenicity of the Vaccine}

(Table 1) shows the distribution of subjects according the sex and immunogenicity. Comparing the different proportions of non-responders according the sex, we find that there is a statistically significant difference between male and female nonresponders $(\mathrm{p}=0.044)$. Impact of the number of doses received on 
the immunogenicity of the vaccine. We found that $90.46 \%$ of the subjects underwent the 0-1-month immunization schedule. While 9.53\% underwent the 0-1-6-month pattern. (Table 2) shows the distribution of subjects according to the number of doses received and the immunogenicity. By comparing the different proportions of non-responders according to the vaccination schedule, it was found that there was no statistically significant difference between subjects who received two doses of those who received three doses $(\mathrm{p}=0.55)$.

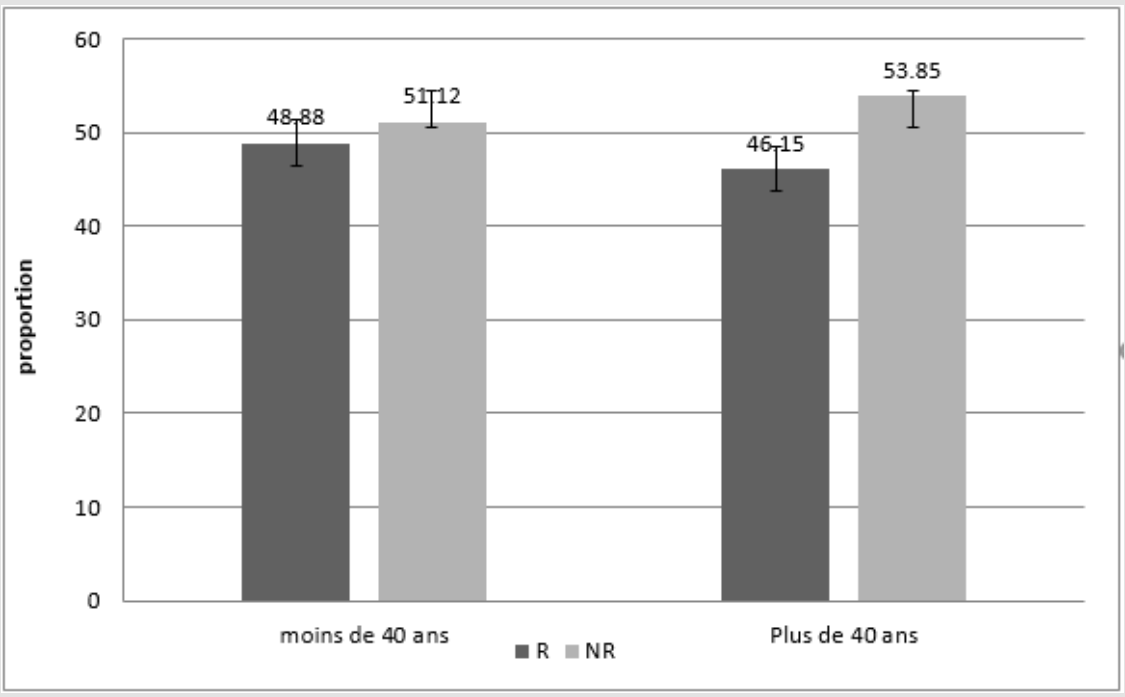

Figure 1: Shows the distribution of subjects according age group and vaccine immunogenicity.

Table 1: Breakdown of subjects by sex and immunogenicity.

\begin{tabular}{|c|c|c|c|}
\hline Sex & Proportion of Responders (\%) & $\begin{array}{c}\text { Proportion of Non Responders } \\
\text { (\%) }\end{array}$ & p-value \\
\hline Male & $30.9(26 / 84)$ & $3809(32 / 84)$ & 0.044 \\
\hline Female & $16.66(14 / 84)$ & $14.28(12 / 84)$ & \\
\hline
\end{tabular}

Table 2: Distribution of subjects according number of doses and immunogenicity.

\begin{tabular}{|c|c|c|c|}
\hline Number of Doses Received & Proportion of Responders (\%) & Proportion of Non-Responders (\%) & P-value \\
\hline 2 & $\mathbf{4 4 . 0 4}(37 / 84)$ & $\mathbf{4 6 . 4 2}(39 / 84)$ & \multirow{2}{*}{0.55} \\
\hline 3 & $3.57(3 / 84)$ & $5.95(5 / 84)$ & \\
\hline
\end{tabular}

\section{Discussion}

We found in our study that subjects with anti-HBs antibodies titer of less than $10 \mathrm{mIU} / \mathrm{mL}$ (non-responder generals) accounted for $22.62 \%$ compared to $77.38 \%$ for subjects with a titre greater than $10 \mathrm{mIU} / \mathrm{ml}$. Regarding non-responders in care settings, we found that $52.4 \%$ of the subjects had an anti-HBs antibodies tire of less than $100 \mathrm{mIU} / \mathrm{ml}$ (non-responders) compared to $47.6 \%$ of subjects with titre greater than or equal to $100 \mathrm{mIU} / \mathrm{ml}$ (good responders). In most immunocompetent studies, $5 \%$ to $10 \%$ of vaccines did not respond to HBV vaccination Barin [5]. Our results corroborate those of some authors who found high proportions of non-responders such as Gargouri [6] (12.1\%) and Abiteboul [7] (15.4\%).

This higher rate of non-responders obtained in the study may be explained by the fact that the protective threshold for neutralizing antibodies in the personnel of the recommended care settings is ten times that recommended by the WHO (anti-HBs titer $<10 \mathrm{mIU}$ / $\mathrm{mL}$ ). To this must be added the influence of the anti-HBs antibodies assay time. Indeed, we performed the HBs antibody assay one year after immunization. And, it is possible that the decrease in antibodies titers over time is an additional argument for our results because sample collection was done on average 12 months after the last dose Bruce [8]. In sum, the ability of SHANVAC B ${ }^{\circledR}$ vaccine to induce, in vaccinated health personnel, the production and persistence of specific neutralizing antibodies beyond a threshold considered protective has been proven.

In our study, we find that there is no statistically significant difference between non-responders aged $\leq 40$ years compared with those of non-responders age $>40$ years $(\mathrm{p}=0.8)$. Our results corroborate those of Treadwell, 1993 and Goldwater, 1997 which showed that one of the factors of less good response to vaccination is age ( $>30$ years for men and $>40$ years for women). Thus, the 
average age of subjects is 40.38 years. These show that most of the vaccines in our study have reached the age at which the immune system does not respond to HBV immunization or poorly. We suggest that early immunization in health care settings in resourcelimited settings could improve the post-vaccination immune response against $\mathrm{HBV}$.

In addition, we found that there is a statistically significant difference between male and non-female responders ( $p=0.044$ ). The possible reasons for a large proportion of non-responders to hepatitis B vaccination in males are still poorly studied. Associated factors such as overweight, smoking, excessive alcohol consumption, HLA DRB1 and DQB1 alleles, and comorbidity: diabetes, renal failure, cirrhosis, immune deficiency (transplantation, infection with HIV, immunosuppressive therapies) may explain the poorer response to hepatitis B vaccination Treadwell [9], Goldwater [10] However, our study did not explore these factors in subjects. By comparing the different proportions of non-responders according to the vaccination schedule, it was found that there was no statistically significant difference between subjects who received two doses of those who received three doses $(p=0.55)$.

Carlsson [11] obtained quite similar results in 1999. They vaccinated some medical staff and compared the effects of the intramuscular and intradermal routes. On the other hand, several other studies aimed at analyzing the possibility of reducing the doses required for vaccination against hepatitis $\mathrm{B}$ have given different results. In adults ( $>40$ years), a 2-dose schedule is clearly inferior to a 3-dose regimen Gellin, [12]. Nevertheless, with a rapid vaccination plan (0-1-2 months) using SHANVAC $B^{\circledR}$ vaccine, it could be possible to protect the health care staff with a better rate of completeness Young [13]. A study on the evaluation of the developmental potential of rapid seroprotect ion was carried out; the beneficial results of a reduced duration vaccine regimen with a new triple antigen vaccine (Hepacare) have been achieved Jeune, $[14,15]$. These results confirmed that accelerated vaccination could be achieved with appropriate protocols. Clearly, protection against hepatitis B could be improved if a shorter vaccination regimen could achieve levels of protection with anti-HBs antibodies.

\section{Conclusion}

This study that we conducted to determine the effective protection of staff shows that $77.38 \%$ of vaccinated persons are protected, according to WHO criteria, with an antibody titer of $\geq 10$ $\mathrm{mIU} / \mathrm{mL}$. Care staff is a target group that requires better protection with a higher anti- HBs titer $(\geq 100 \mathrm{mIU} / \mathrm{mL})$. In this specific group the seroprotect ion rate is $47.61 \%$. Although satisfying this rate can be improved.

\section{Contributions of the Authors}

Design and realization of experimental protocols: SY SM OSM TY. Analyze the data: SY SM GMK TY. Contribution in reagents / materials / SY SM TY. Article writing: SY SG. TY SM FF OSM. All authors have read and approved the manuscript.

\section{Competing Interests}

We declare here that there is no conflict of interest.

\section{Declarations}

Funding: No funding was obtained for this study.

\section{Acknowledgements}

We greatly appreciate the Director and health personal of CHU Sourô Sanou. We also acknowledge M. Joseph BAMOUNI for his value assistance in analysis of data.

\section{References}

1. Tao I, Compaoré TR, Diarra B, Florencia D, Theodora MZ, et al. (2014) Seroepidemiology of Hepatitis B and C Viruses in the General Population of Burkina Faso. Hepatitis Research and Treatment.

2. Simpore J, Savadogo A, Ilboudo D, Nadambega MC, Esposito M, et al. (2006) Toxoplasma gondii, HCV and HBV seroprevalence and coinfection among HIV-positive and -negative pregnant women in Burkina Faso. J Med Virol 78(6): 730-733.

3. (2017) WHO, Hepatitis B vaccines: Summary note - July 2017 Weekly epidemiological record 92(27): 369-392.

4. (2014) High Council of Public Health. Notice regarding accelerated hepatitis B vaccine schedules with Engerix B $\AA^{8} 20 \mu \mathrm{g} / 1 \mathrm{ml}$ Genhevac B Pasteur ${ }^{\circledR} 20 \mu \mathrm{g} / 0.5 \mathrm{ml}$ vaccines.

5. Barin F, Denis F, Chiron JP (1982) Immune response in neonates to hepatitis B vaccine. The Lancet 319(8266): 251-253.

6. Gargouri I, Jmal Lhammami K, Sobaszek A, Masmoudi H, Karray H, et al. (2011) Hepatitis B vaccination at public health establishments in Sfax (Tunisia). Archives of occupational diseases and the environment 72(1): 36-40.

7. Abiteboul D, Gouaille B, Proteau J (1990) Prevention of viral hepatitis $B$ at public assistance-hospitals in Paris: assessment of 7 years of vaccination by occupational physicians. Archives of occupational diseases of occupational medicine and social security 51(6): 405-412.

8. Bruce M, Bruden DJ, Hurlburt D (2013) Antibody levels and protection after hepatitis B vaccine: results of a 30-year follow-up study and response to à booster dose. Hepatology 58: 300 .

9. Treadwell TL, Keeffe EB, Lac J, Read A, Friedman LS, et al. (1993) Immunogenicity of two recombinant hepatitis B vaccines in the elderly. Am J Med 95(6): 584-588.

10. Goldwater PN (1997) Comparative randomized trial of 20 micrograms against 40 micrograms of Engerix B vaccine in non-responder's hepatitis B vaccine. Vaccine 15(4): 353-356.

11. Carlsson T, J Struve, Sönnerborg A, Weiland O (1999) The Anti-HBs response after 2 different accelerated and intramuscular intradermal regimens for hepatitis B vaccination. Scand J Infect Dis 31: 93-95.

12. Gellin BG, Greenberg RN, Hart RH, Bertino JS, Stein DH, et al. (1997) Immunogenicity of two doses of yeast recombinant hepatitis $B$ vaccine in healthy older adults. J Infect Dis 175(6): 1494-1497.

13. Young JH, Lugovoy JM, Gilbert RB (1996) Transient hepatitis B surface antigenemia after vaccination in a hemodialysis patient. Journal of the American society of nephrology 7(9): 351.

14. Jeune MD, Rosenthal MH, Dickson B, Du W, Maddrey WC, et al. (2001) A multicenter controlled study of rapid hepatitis $B$ vaccination using a new recombinant triple antigen vaccine. Vaccine 19: 3437-3443.

15. Bryan JP, Sjogren MH, Perine PL, Legters LJ (1992) Low-dose intradermal and intramuscular vaccination against hepatitis B. Clin Infect Dis 14(3): 697-707. 


\section{ISSN: 2574-1241}

DOI: 10.26717/BJSTR.2020.24.004094

Yacouba Sourabié. Biomed J Sci \& Tech Res

(C) (P) This work is licensed under Creative

Submission Link: https://biomedres.us/submit-manuscript.php

$\begin{array}{ll}\text { BIOMEDICAL } & \text { Assets of Publishing with us } \\ \text { RESEARCHES } & \text { - Global archiving of articles } \\ & \text { - Immediate, unrestricted online access } \\ & \text { - Rigorous Peer Review Process } \\ & \text { - Authors Retain Copyrights } \\ \end{array}$

